\title{
THE EFFECT OF COOLING RATE ON THE MAGNETIC PROPERTIES OF Cu-Fe-Ni MULTICOMPONENT ALLOYS WITH Al AND Si ADDITIONS
}

\author{
O. I. Kushnerov*, V. F. Bashev \\ Oles Honchar Dnipro National University, Dnipro, Ukraine \\ *e-mail:kushnrv@gmail.com
}

\begin{abstract}
The paper explores the structure and magnetic properties of multicomponent high-entropy Al-Cu-FeNi-Si alloys in as-cast and splat-quenched state. This alloy system is characterized by the absence of expensive components, such as $\mathrm{Co}, \mathrm{V}, \mathrm{Mo}, \mathrm{Cr}$, usually used for the production of high-entropy alloys while its characteristics are not inferior to those of more expensive alloys. Components of the studied highentropy alloys were selected taking into account both criteria for designing and estimating their phase composition, which are available in the literature and based on the calculations of the entropy and enthalpy of mixing, and the difference between atomic radii of components as well. The alloy films were fabricated by a known technique of splat-quenching. A cooling rate estimated by film thickness was $\sim 10^{6} \mathrm{~K} / \mathrm{s}$. Experimental results reveal that the studied alloys except the $\mathrm{Al}_{0.5} \mathrm{CuFeNi}$ one are multiphase, with the structure consisting of disordered $\mathrm{BCC}$ and $\mathrm{FCC}$ solid solutions. The $\mathrm{Al}_{0.5} \mathrm{CuFeNi}$ alloy has only $\mathrm{FCC}$ phase. The leading role in determining the type of solid solution formed in the studied high-entropy films obviously plays an element with the highest melting point. All of the investigated multicomponent films are soft magnetic materials as indicated by low values of coercivity, while most of the as-cast alloys are hardmagnetic.
\end{abstract}

Keywords: high-entropy alloy, structure, magnetic properties, splat-quenching.

Received 12.09.2018; Received in revised form 02.10.2018; Accepted 14.11.2018

\section{Introduction}

The first results on multi-component and high entropy crystalline alloys were published in 2004. Such alloys usually contain from 5 to 13 major elements in equiatomic or near equiatomic concentrations (5 to $35 \%$ ). Due to the high mixing entropy, multicomponent high entropy alloys (HEAs) typically consist of simple solid solutions with a BCC or FCC lattices [1, 2].Choosing the amount of components and their concentration allows one to achieve increased entropy of mixing, which remains not only in the melt but after solidification. Because of the high entropy, usually simple substitutional solid solutions with BCC or FCC crystal lattices are formed during the solidification of multicomponent alloys. At the same time, the purposeful selection of components allows one to obtain the structure of HEA, which is a combination of a simple solid solution characterized by high plasticity and intermetallic compounds ( $\sigma$ phase, Laves phases) characterized by high hardness $[1,2]$. The HEAs are characterized by unique structures and a number of useful service characteristics, such as hardness, wear-resistance, resistance to oxidation, corrosion, and ionizing radiation, high thermal stability and biocompatibility [1-6]. Also the study of high-entropy metallic glasses and alloys with shape memory are published [7-10]. Thus, the HEAs show promise as materials for application in electronics, atomic power engineering, transportation equipment, space-rocket hardware, medicine etc.

High-entropy alloys usually characterizing by the entropy of mixing $\Delta S_{m i x}$ and mixing enthalpy $\Delta H_{m i x}$. But to describe the phase composition of HEAs some empirical criteria were proposed, namely, the atomic-size difference which is described by the parameter $\delta$, valence electron concentration VEC and the thermodynamic $\Omega$ parameter, which correlates the melting point, entropy of mixing, and the enthalpy of mixing. The definitions of these parameters were considered in many works [1]. But much less attention was paid to the physical properties of HEAs, so this paper is devoted to the investigation of magnetic properties of multicomponent alloys of $\mathrm{Cu}-\mathrm{Fe}-\mathrm{Ni}$ alloy system with $\mathrm{Al}$ and $\mathrm{Si}$ additions in 
as-cast and splat-quenched state. The alloys of this system are characterized by the absence of expensive components, such as $\mathrm{Co}, \mathrm{V}, \mathrm{Mo}, \mathrm{Cr}$, usually used for the HEAs production while their characteristics are not inferior to those of more expensive alloys. Design of such alloys is one of perspective directions in the development of advanced HEAs [11].

\section{Experimental procedure}

The samples of Al-Cu-Fe-Ni-Si multicomponent alloys (Tab.1) were taken from the as-cast ingots, prepared by a laboratory Tamman furnace in the flow of argon and poured into a copper mold (the average cooling rate is $\sim 10^{2} \mathrm{~K} / \mathrm{s}$ ). The mass losses during melting did not exceed $1 \%$. The quenching was performed by splat cooling technique; in this case, cooling is achieved via the collision of melt drops with the internal surface of rapidly rotating copper cylinder. To estimate the cooling rate, we used the procedure suggested in $[12,13]$ and the expression (1)

$$
V=\frac{\alpha \vartheta}{c \rho \delta}
$$

where $\alpha$ is the heat transfer coefficient, $\vartheta$ is the excess temperature of film, $c$ is the heat capacity of film material, $\rho$ is the density of film material, and $\delta$ is the film thickness. Taking into account the thickness of splat-quenched (SQ) films, i.e., $\sim 50 \mu \mathrm{m}$, the estimated cooling rate was $\sim 10^{6} \mathrm{~K} / \mathrm{s}$. The X-ray phase diffraction (XRD) analysis was performed using a DRON-2.0 diffractometer and $\mathrm{Cu} K \alpha$ monochromatized radiation. The patterns were processed using a QualX [14] and FullProf software [15]. The magnetic properties of the samples were measured by a vibrating sample magnetometer (VSM) at room temperature with the magnetic field applied parallel to the sample plane. The coercive force $\left(H_{C}\right)$ was measured with a B-H loop tracer.

\section{Results and discussion}

The phase composition of investigated alloys, crystal lattice parameters and the crystalline sizes (Tab.1) were determined from the XRD patterns (Fig.1).

Phase composition, lattice parameters and crystalline sizes $(L)$ of the Al-Cu-Fe-Ni-Si HEA films

\begin{tabular}{|c|c|c|c|}
\hline Alloy & Phase composition & Lattice parameter $a, \mathrm{~nm}$ & $L, \mathbf{n m}$ \\
\hline \multirow{2}{*}{$\mathrm{CuFeNiSi}_{0.5} \mathrm{SQ}$} & $\operatorname{FCC}(88.9 \%)$ & 0.3586 & $27 \pm 3$ \\
\hline & $\operatorname{BCC}(11.1 \%)$ & 0.2801 & $21 \pm 2$ \\
\hline \multirow{2}{*}{$\mathrm{CuFeNiSi}_{0.5}$ as-cast } & FCC $(83.1 \%)$ & 0.3635 & $18 \pm 2$ \\
\hline & $\operatorname{BCC}(16.9 \%)$ & 0.2801 & $15 \pm 2$ \\
\hline $\mathrm{Al}_{0.5} \mathrm{CuFeNi} \mathrm{SQ}$ & FCC (100\%) & 0.3616 & $32 \pm 3$ \\
\hline $\mathrm{Al}_{0.5} \mathrm{CuFeNi}$ as-cast & FCC (100\%) & 0.3608 & $24 \pm 3$ \\
\hline \multirow{2}{*}{$\mathrm{Al}_{0.7} \mathrm{CuFeNi} \mathrm{SQ}$} & FCC (73.2\%) & 0.3622 & $28 \pm 3$ \\
\hline & $\mathrm{BCC}(26.8 \%)$ & 0.2879 & $18 \pm 2$ \\
\hline \multirow{2}{*}{$\mathrm{Al}_{0.7} \mathrm{CuFeNi}$ as-cast } & FCC (59.3\%) & 0.3622 & $19 \pm 3$ \\
\hline & BCC (40.7\%) & 0.2891 & $13 \pm 2$ \\
\hline \multirow{2}{*}{$\mathrm{Al}_{0.5} \mathrm{CuFeNiSi}_{0.25} \mathrm{SQ}$} & FCC (13.3\%) & 0.3619 & $36 \pm 3$ \\
\hline & $\operatorname{BCC}(86.7 \%)$ & 0.2863 & $23 \pm 2$ \\
\hline \multirow{2}{*}{$\mathrm{Al}_{0.5} \mathrm{CuFeNiSi}_{0.25}$ as-cast } & FCC $(26.9 \%)$ & 0.3626 & $24 \pm 3$ \\
\hline & $\operatorname{BCC}(73.1 \%)$ & 0.2867 & $15 \pm 2$ \\
\hline \multirow{2}{*}{$\mathrm{Al}_{0.25} \mathrm{CuFeNiSi}_{0.25} \mathrm{SQ}$} & FCC $(86.5 \%)$ & 0.3602 & $30 \pm 3$ \\
\hline & BCC (13.5\%) & 0.2844 & $15 \pm 2$ \\
\hline \multirow{2}{*}{$\mathrm{Al}_{0.25} \mathrm{CuFeNiSi}_{0.25}$ as-cast } & FCC $(87.5 \%)$ & 0.3604 & $17 \pm 3$ \\
\hline & $\operatorname{BCC}(12.5 \%)$ & 0.2844 & $16 \pm 2$ \\
\hline
\end{tabular}




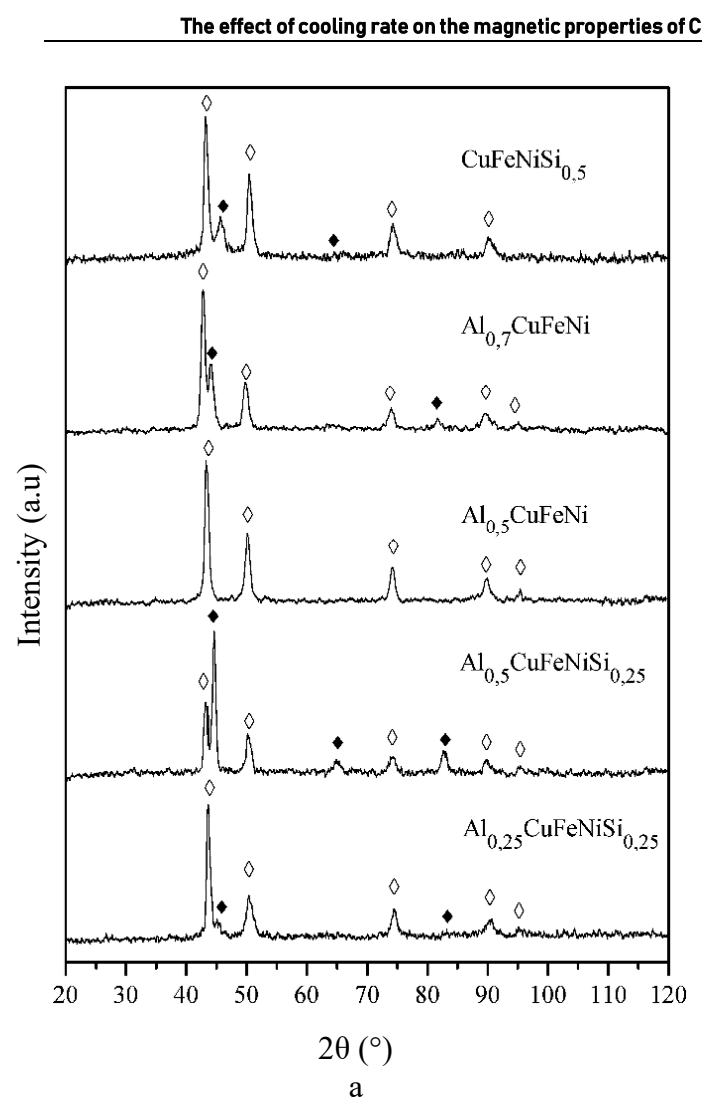

Fig. 1. XRD patterns of the as-cast samples (a) and splat-quenched films (b)

of Al-Cu-Fe-Ni-Si alloy system: $\diamond$-FCC, $\diamond-B C C$.

From the results of analysis of the XRD patterns, it is apparent that all of the investigated alloys, except the $\mathrm{Al}_{0.5} \mathrm{CuFeNi}$ one, have similar reflections of simple $\mathrm{BCC}$ and FCC solid solutions both in the as-cast and in the SQ state. The $\mathrm{Al}_{0.5} \mathrm{CuFeNi}$ alloy consists of only simple FCC solid solution. At the same time, nominal chemical compositions of all investigated alloys were chosen so that their VEC values were favored to the formation of an FCC phase. Such deviations from the predicted structure type have been observed in several works [16]. Obviously, as proposed in [17], it must be assumed that the exact boundaries of the valence electron concentration range in which we should expect the formation of two-phase solid solutions based on the FCC and BCC lattices are individual for each alloy system. The values of lattice parameters of the investigated alloys suggest that the solid solutions are formed on the base of iron's lattice $(\gamma-\mathrm{Fe}, \mathrm{a}=0.3572 \mathrm{~nm}$ and $\alpha-\mathrm{Fe}, \mathrm{a}=0.2866 \mathrm{~nm})$, in view of its highest melting temperature.

Using the data from [13], following quantities were calculated for the HEA films (as listed in Tab.2): $\Delta S_{m i x}, \Delta H_{m i x}, \delta, \Omega$ and VEC. It should be noted that, in accordance with the calculated values of $\Delta S_{m i x}$ the majority of the alloys studied in this paper formally must be attributed to medium entropy alloys [1], however, taking into account the evaluation of the minimum entropy of mixing for the HEAs $\Delta S_{m i x} \geq 11 \mathrm{~J} /(\mathrm{mol} \mathrm{K})$, given in [15] many researchers consider such alloys as high-entropy.

The magnetic hysteresis curves of the Al-Cu-Fe-Ni-Si HEAs in as-cast and splatquenched state at room temperature are given in Fig. 2-6. The all of samples show a pronounced ferromagnetic behavior (Tab.3). According to the coercivity $\left(\mathrm{H}_{\mathrm{c}}\right)$ of 
investigated SQ films, they can be attributed to soft magnetic materials. $H_{c}$ is related to the shape, size and dispersion degree of the crystalline grains, internal stress and lattice distortion. In our opinion, the soft magnetic behavior of Al-Cu-Fe-Ni-Si HEA films can be explained by the occurrence of a nanocrystalline structure during the splat-quenching. Consequently, the grain sizes and intergranular distances become less than the ferromagnetic exchange correlation length, giving rise to the magnetic softening [16]. Magnetization $M$ of the alloy depends mainly on the composition and crystal structure, so comparing the values of $M$ and BCC phase content from Tab.1 one can see that BCC phase is characterized by stronger ferromagnetic properties than FCC. We can explain this by the fact that it is based on a lattice of ferromagnetic $\alpha-\mathrm{Fe}$.

Table 2

\begin{tabular}{|c|c|c|c|c|c|}
\hline Alloy & $\Delta \mathbf{H}_{\text {mix }}, \mathbf{k J} / \mathbf{m o l}$ & $\Delta \mathbf{S}_{\operatorname{mix}}, \mathbf{J} /(\mathrm{mol} \cdot \mathbf{K})$ & $\delta$ & VEC & $\boldsymbol{\Omega}$ \\
\hline $\mathrm{CuFeNiSi}_{0.5}$ & -10.45 & 11.23 & 2.51 & 8.86 & 1.76 \\
\hline $\mathrm{Al}_{0.7} \mathrm{CuFeNi}$ & -3.18 & 11.43 & 5.11 & 8.41 & 5.39 \\
\hline $\mathrm{Al}_{0.5} \mathrm{CuFeNi}$ & -1.14 & 11.23 & 4.62 & 8.71 & 15.02 \\
\hline $\mathrm{Al}_{0.5} \mathrm{CuFeNiSi}_{0.25}$ & -8.36 & 12.52 & 4.95 & 8.4 & 2.31 \\
\hline $\mathrm{Al}_{0.25} \mathrm{CuFeNiSi}{ }_{0.25}$ & -6.18 & 12.06 & 4.00 & 8.79 & 3.09 \\
\hline
\end{tabular}
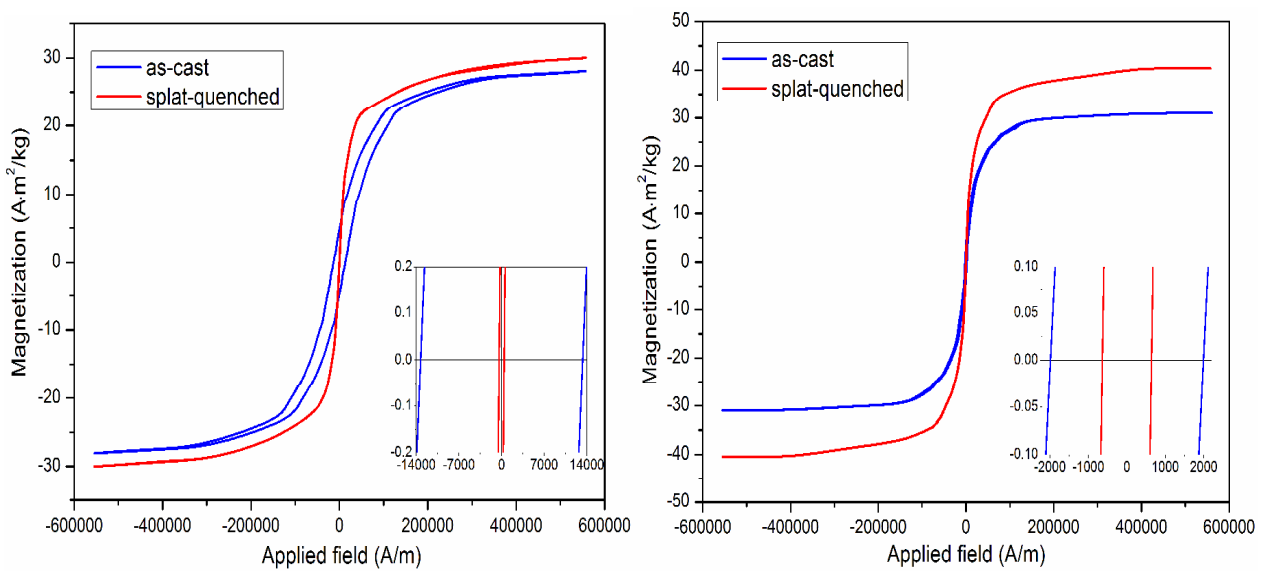

Fig.2. Hysteresis loops of $\mathrm{CuFeNiSi}_{0.5}$ HEA.

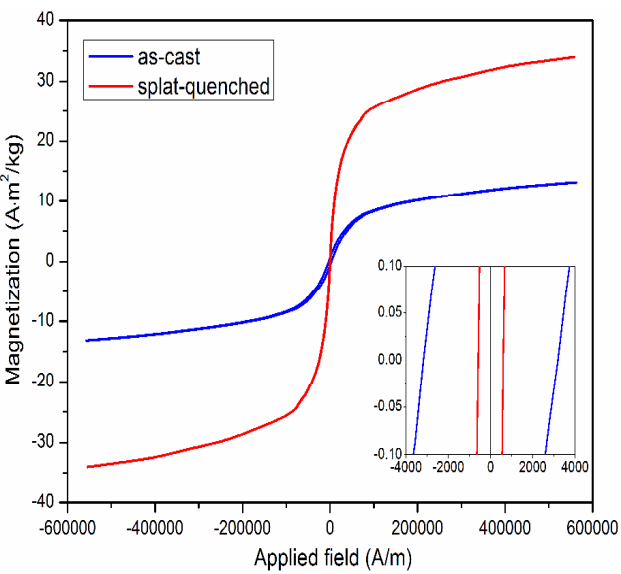

Fig.4. Hysteresis loops of $\mathrm{Al}_{0.7} \mathrm{CuFeNi} \mathrm{HEA}$.

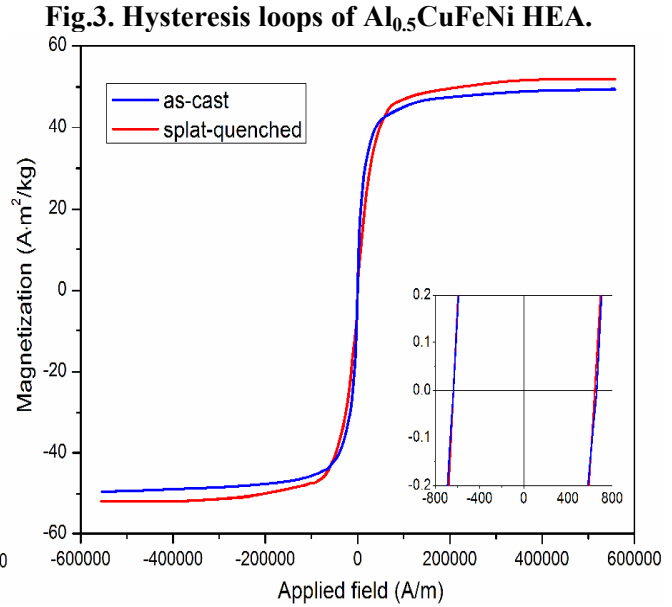

Fig.5. Hysteresis loops of $\mathrm{Al}_{0.5} \mathrm{CuFeNiSi}_{0.25} \mathrm{HEA}$. 


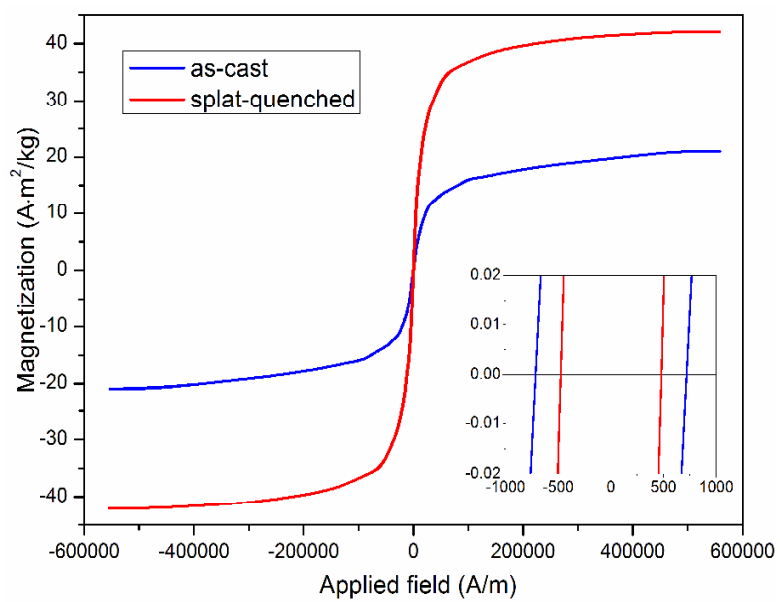

Fig.6. Hysteresis loops of $\mathrm{Al}_{0.25} \mathrm{CuFeNiSi}_{0.25} \mathrm{HEA}$.

At the same time, most of the as-cast alloys are hard-magnetic, so decrease in the cooling rate results in an increase in the coercive force for all the samples under study. The magnetization $M$ of the as-cast alloys also decreases. This can be explained by the more uniform distribution of the atoms in SQ films, while in the cast alloys formed the dendritic structure with subsequent collapse. It should be noted that the study of the fine structure of the HEAs by the methods of high-resolution electron microscopy usually shows also the presence of nanosized intermetallic precipitates [22].The above factors should complicate the processes of the domain boundary movement and the process of remagnetization.

Table 3

Magnetic characteristics of Al-Cu-Fe-Ni-Si HEA alloys

\begin{tabular}{|c|c|c|c|c|}
\hline \multirow{2}{*}{ Alloy } & \multicolumn{2}{|c|}{ Specific magnetization $\boldsymbol{M}_{\boldsymbol{S}}, \mathbf{A} \cdot \mathbf{m}^{\mathbf{2}} / \mathbf{k g}$} & \multicolumn{2}{c|}{ Coercivity $\boldsymbol{H}_{\boldsymbol{c}}, \mathbf{A} / \mathbf{m}$} \\
\cline { 2 - 5 } & $\mathbf{S Q}$ & $\mathbf{A s - c a s t}$ & SQ & As-cast \\
\hline $\mathrm{Al}_{0.5} \mathrm{CuFeNi}$ & $30 \pm 3$ & $28 \pm 3$ & $400 \pm 80$ & $13300 \pm 500$ \\
\hline $\mathrm{Al}_{0.5} \mathrm{CuFeNiSi}$ & & $640 \pm 50$ & $640 \pm 50$ \\
\hline $\mathrm{Al}_{0.7} \mathrm{CuFeNi}$ & $52 \pm 5$ & $49 \pm 5$ & $600 \pm 50$ & $3200 \pm 300$ \\
\hline $\mathrm{Al}_{0.25} \mathrm{CuFeNiSi}_{0.25}$ & $34 \pm 3$ & $13 \pm 1$ & $480 \pm 50$ & $720 \pm 80$ \\
\hline $\mathrm{CuFeNiSi}_{0.5}$ & $42 \pm 4$ & $21 \pm 2$ & $640 \pm 50$ & $2000 \pm 100$ \\
\hline
\end{tabular}

\section{Conclusions}

In this study, five alloys of $\mathrm{Al}-\mathrm{Cu}-\mathrm{Fe}-\mathrm{Ni}$-Si HEA system in the as-cast and splatquenched state were prepared. All the alloys, except the $\mathrm{Al}_{0.5} \mathrm{CuFeNi}$, exhibits a simple BCC and FCC solid solutions. The $\mathrm{Al}_{0.5} \mathrm{CuFeNi}$ film consists of only simple $\mathrm{FCC}$ solid solution. The leading role of the element with a highest melting temperature as the basis for the formation of solid solution in the studied alloys is confirmed. Explored films show a ferromagnetic properties with specific magnetization $M_{S}$ in the range of $28-49$ $\mathrm{A} \cdot \mathrm{m}^{2} / \mathrm{kg}$. The coercivity $H_{c}$ is around $400-640 \mathrm{~A} / \mathrm{m}$, so Al-Cu-Fe-Ni-Si splat-quenched films can be referred to soft magnetic materials. The as-cast alloys characterized by lower values of magnetization and most of them are hard magnetic. 


\section{References}

1. High-entropy alloys. Fundamentals and Applications / ed. M. C. Gao, ed. J.-W. Yeh, ed. P. K. Liaw, ed. Y. Zhang. - Springer International Publishing, 2016. -516 p.

2. Gao M. High-entropy alloys (HEAs) / M. Gao, J. Qiao // Metals. - 2018. - Vol. 8, No. 2. - P. 108-110.

3. Firstov, G. S. High entropy shape memory alloys / G. S. Firstov, T. A. Kosorukova, Y. N. Koval, V. V Odnosum // Materials Today: Proceedings. - 2015. - V. 2. - P. S499-S503.

4. Bashev, V. F. Structure and properties of high entropy $\mathrm{CoCrCuFeNiSn}$ alloys / V. F. Bashev, O. I. Kushnerov // The Physics of Metals and Metallography. $-2014,-$ V. 115, No. 7,-P. 692-696.

5. Miracle, D. B. A critical review of high entropy alloys and related concepts / D. B. Miracle, O. N. Senkov // Acta Materialia. - 2017. - Vol. 122. - P. 448-511.

6. Wang, S. TiZrNbTaMo high-entropy alloy designed for orthopedic implants: ascast microstructure and mechanical properties / S. Wang, J. Xu // Materials Science and Engineering: C. - 2017. - Vol. 73.- P. 80-89.

7. Li, Y. New soft magnetic $\mathrm{Fe}_{25} \mathrm{Co}_{25} \mathrm{Ni}_{25}(\mathrm{P}, \mathrm{C}, \mathrm{B})_{25}$ high entropy bulk metallic glasses with large supercooled liquid region / Y. Li, W. Zhang, T. Qi // Journal of Alloys and Compounds. - 2017. - Vol. 693. - P. 25-31.

8. Qi, T. Soft magnetic $\mathrm{Fe}_{25} \mathrm{Co}_{25} \mathrm{Ni}_{25}(\mathrm{~B}, \mathrm{Si})_{25}$ high entropy bulk metallic glasses / T. Qi, Y. Li, A. Takeuchi, G. Xie, H. Miao // Intermetallics. - 2015. -V. 66. - P. 8-12.

9. Wei, R. Soft magnetic $\mathrm{Fe}_{26.7} \mathrm{Co}_{26.7} \mathrm{Ni}_{26.6} \mathrm{Si}_{9} \mathrm{~B}_{11}$ high entropy metallic glass with good bending ductility / R. Wei, J. Tao, H. Sun, C. Chen, G. W. Sun, F. S. Li // Materials Letters. - 2017. - Vol. 197. - P. 87-89.

10. Ding, J. High entropy effect on structure and properties of ( $\mathrm{Fe}, \mathrm{Co}, \mathrm{Ni}, \mathrm{Cr})-\mathrm{B}$ amorphous alloys / J. Ding, A. Inoue, Y. Han, F. L. Kong, S. L. Zhu, Z. Wang, E. Shalaan, F. Al-Marzouki // Journal of Alloys and Compounds. - 2017. - Vol. 696. - P. 345-352.

11. Tsai, M.-H. Three strategies for the design of advanced high-entropy alloys / M.-H. Tsai // Entropy. - 2016. - Vol. 18, No. 7. - P. 252-265.

12. Miroshnichenko, I. S., Quenching from the Liquid State / I.S. Miroshnichenko. -Metallurgiya, Moscow, 1982. - 168 p. (in Russian).

13. Bashev, V. F. Structure and properties of cast and splat-quenched high-entropy $\mathrm{Al}-\mathrm{Cu}-\mathrm{Fe}-\mathrm{Ni}-\mathrm{Si}$ alloys / V. F. Bashev, O. I. Kushnerov // Physics of Metals and Metallography. - 2017. - Vol. 118, No. 1. - P. 39-47.

14. Krapivka N. A. Features of phase and structure formation in high-entropy alloys of the AlCrFeCoNiCux system ( $\mathrm{x}=0,0.5,1.0,2.0,3.0)$ / N. A. Krapivka, S. A. Firstov, M. V Karpets, A. N. Myslivchenko, V. F. Gorban // The Physics of Metals and Metallography. - 2015. - Vol. 116, No. 5. - P. 467-474.

15. Guo, S. Phase stability in high entropy alloys: Formation of solid-solution phase or amorphous phase /S. Guo, C.T.Liu// Progress in Natural Science: Materials International.-2011.-V. 21, Iss. 6. - P. 433 - 446.

16. Gulivets, A. N. Multilayer compound Co-P films with controlled magnetic properties / A. N. Gulivets, V. A. Zabludovsky, E. P. Shtapenko, A. I. Kushnerev, M. P. Dergachov, A. S. Baskevich // Transactions of the IMF. - 2002. - Vol. 80, No. 5. - P. 154-156.

17. Ivchenko M. V. Specific features of cast high-entropy alcrfeconicu alloys produced by ultrarapid quenching from the melt / M. V. Ivchenko, V. G. Pushin, a. N. Uksusnikov, N. Wanderka, N. I. Kourov // The Physics of Metals and Metallography. 2013. - Vol. 114, No. 6. - P. 503-513. 